\title{
IN VITRO STUDY ON ANTIOXIDANT ACTIVITY OF METHANOLIC LEAF EXTRACT OF PIPER BETLE LINN
}

Bindhu R. Kamath', Sabeena $K^{2}$

${ }^{1}$ Assistant Professor, Department of Pharmacology, Government Medical College, Ernakulam, Kerala, India.

${ }^{2}$ Associate Professor, Department of Pharmacology, Government Medical College, Ernakulam, Kerala, India.

\begin{abstract}
BACKGROUND
The use of medicinal plants for maintaining good health is getting attention worldwide. Antioxidants play an important role in preventing damage caused by oxidative stress. In the present study, methanolic leaf extract of Piper betle Linn plant of central Kerala was evaluated for antioxidant activity. Phytochemical investigation confirmed the presence of bioactive ingredients in the extract.
\end{abstract}

ABSTRACT

\section{MATERIALS AND METHODS}

The antioxidant activity of methanolic extract of Piper betle Linn leaf was evaluated using DPPH free radical assay. DPPH (1, 1diphenyl-2-picrylhydrazyl) free radical analysis is one of the accurate and frequently employed methods for evaluating antioxidant activity.

\section{RESULTS}

The methanolic leaf extract of Piper betle Linn demonstrated antioxidant activity. As concentration increases, radical scavenging activity increases.

\section{CONCLUSION}

Scientific evidence suggests that antioxidants reduce the risk for chronic diseases including cancer and heart disease and infectious diseases. Further evaluation of pharmacological activities of Piper betle may prove useful in treatment of cancer and heart diseases.

\section{KEY WORDS}

Piper betle Linn, DPPH, Antioxidant Activity.

HOW TO CITE THIS ARTICLE: Kamath BR, Sabeena K. In vitro study on antioxidant activity of methanolic leaf extract of piper betle linn. J. Evolution Med. Dent. Sci. 2018;7(24):2865-2869, DOI: 10.14260/jemds/2018/646

\section{BACKGROUND}

Piper betle belonging to piperaceae family is one of the precious medicinal herbs found in central and eastern Malaysia and south-east Asia. In India it is commonly known as Paan, which is second to tea and coffee based on daily consumption. ${ }^{1}$ Betle leaves are very nutritive and contain vitamins and minerals. ${ }^{2}$ Scientific research on betle leaves reveals that it possesses many beneficial bioactivities and its extract has a great potential to be used in developing commercial products. ${ }^{3}$

The consumption of antioxidants rich food helps in neutralising the free radical in the body. It will prevent and delay the oxidative damage of lipids, proteins and nucleic acids. ${ }^{4}$ Studies have shown that in Cardiovascular diseases, antioxidants can reduce mortality rate. Similar benefits are seen against many chronic diseases and cancer. ${ }^{5}$

Piper betle Linn (Piperaceae), paan is widely used as a post meal mouth freshener. Pharmacological profile has shown antiplatelet, anti-inflammatory effects as well as

'Financial or Other Competing Interest': Dr. Kamath reports grants from State Board of Medical Research, Kerala, during the conduct of the study.

Submission 26-04-2018, Peer Review 29-05-2018,

Acceptance 04-06-2018, Published 11-06-2018.

Corresponding Author:

Dr. Sabeena $K$,

Associate Professor, Department of Pharmacology,

Government Medical College,

Ernakulam, Kerala, India.

E-mail: drsabeenakizhedath@gmail.com

DOI: $10.14260 /$ jemds $/ 2018 / 646$ immunomodulatory, gastroprotective and anti-diabetic activity. Piper betle leaf is popular as an antiseptic and is commonly applied on wounds and lesions for its healing effects. The leaves are nutritive and contain anticarcinogen principles. ${ }^{6}$ Piper betle has its use in Ayurveda medicine from time immemorial. The use of Piper betle leaves as medicine, mouth freshener can be traced back to two thousand years. In our country, chewing betle leaves with Areca nut and other adjuvants is prevalent. Aromatic oil, glycosides, vitamins, minerals, tannins and amino acids are the important principles present in betle leaves. ${ }^{6}$

Antioxidant supplements or antioxidant rich food can help in reducing the oxidative damage from free radicals and active oxygen species. Due to the toxicity of antioxidants, emphasis is given on development and isolation of natural antioxidants from plant species. ${ }^{7}$ Aqueous extracts of inflorescence Piper Betle was shown to be a scavenger of $\mathrm{H}_{2} \mathrm{O}_{2}$, superoxide radical and hydroxyl radical. ${ }^{8}$

Plants that have significant antioxidant properties are found to be rich in phenolic content. ${ }^{9}$ This correlation between antioxidant activity and phenolic content has been confirmed with the similar studies. The betel leaf extract possesses anticarcinogenic, antimutagenic, antiplaque, C, anti-inflammatory and antibacterial properties. ${ }^{10}$

Polyphenol-rich extract of PBI and BQ were potent DPPH scavengers, having similar activity to quercetin and were able to protect LDL from oxidation, but were pro-oxidants at lower concentrations, suggesting the possibility of protective effect against atherosclerosis. ${ }^{11}$ Soxhlet extraction has the most used extraction techniques worldwide for a number of 
decades surpassing the performance of other extraction alternatives. ${ }^{12}$

Natural products are now increasing in demand, because of the presence of active principles which are useful against a large number of diseases. The phenolic and other bioactive compounds in betle leaves make it a useful natural product in prophylaxis and in treatment of chronic inflammatory diseases. ${ }^{6}$

Plants growing in different climatic and seasonal conditions do not have identical constituents or therapeutic effects. Thus active components may differ in nature or concentration. Phytochemical analysis of the crude extract can indicate the presence of active constituents in the plant. There are not much documented studies testing the effectiveness of Piper betle grown in central Kerala. In this scenario, the present study was conducted to find out the antioxidant activity of Piper betle grown in this place.

\section{MATERIALS AND METHODS}

Study Design

Descriptive Study.

\section{Study Period}

1 year.

\section{Study Setting}

1. Department of Pharmacology, Government Medical College, Ernakulam.

2. CARE Keralam Ltd., Koratty.

\section{Study Tool}

Equipments: Soxhlet apparatus, UV-VIS Spectrophotometer.

\section{Analytical Reagents}

Methanol, DPPH, Ascorbic Acid.

\section{Study Procedure}

\section{a. Collection of Plant Materials}

Fresh leaves of Piper betle were collected from household near GMC, Ernakulam campus in month of MayJune. Leaves were shade dried and crushed into fine powder with electric blender. The powdered sample were sealed in polythene box and stored.

b. Preparation of Methanolic Extract- Sample Preparation

Preparation of methanol extract: Dried and powdered leaves (25 g) were used. The extract is prepared using Soxhlet apparatus. Powdered leaves with $200 \mathrm{~mL}$ of methanol were subjected for extraction for about $10 \mathrm{~h}$ in a water bath. The crude plant extract in solvent was removed from the Soxhlet apparatus and concentrated to dryness in water bath. $8 \mathrm{mg}$ of the concentrated extract was yielded, which is stored in refrigerator.

\section{Phytochemical Screening}

Preliminary phytochemical screening was performed by using the following standard tests.

\section{Test for Alkaloids}

Dragendorff's test: $1 \mathrm{~mL}$ of extract $+1 \mathrm{~mL}$ of Mayer's reagent. Yellow precipitate confirmed the presence of alkaloids.

\section{Glycosides}

$1 \mathrm{~mL}$ of extract $+1 \mathrm{~mL}$ of water + Aq. $\mathrm{NaOH}$. Yellowish brown precipitate, which confirmed the presence of Glycosides.

\section{Flavonoids}

$1 \mathrm{~mL}$ extract $+10 \%$ lead acetate. Yellowish green precipitate confirms the presence of flavonoids.

\section{Saponins}

$1 \mathrm{~mL}$ extract + boiled with $1 \mathrm{~mL}$ of distilled water. No froth was seen, which indicates the absence of saponins.

\section{Tannins}

$1 \mathrm{~mL}$ extract $+0.1 \% \mathrm{FeCl}_{3}$. Brownish green precipitate, which confirms the presence of tannins.

\section{Terpenoids}

$1 \mathrm{~mL}$ extract $+1 \mathrm{~mL}$ of $\mathrm{CHCl}_{3}+2 \mathrm{~mL}$ conc. $\mathrm{H}_{2} \mathrm{SO}_{4}$. Brown precipitate was obtained, which indicate the presence of terpenoids.

\section{Proteins}

$1 \mathrm{~mL}$ extract $+1 \mathrm{~mL} 40 \% \mathrm{NaOH}+2$ drops of $1 \% \mathrm{CuSO}_{4}$. No visible Pink colour, so no proteins are present.

\section{Carbohydrates}

Benedict's Test: $1 \mathrm{~mL}$ extract $+5 \mathrm{~mL}$ Benedict's reagent. Boiled for 2 minutes and cooled. Slight red precipitate, which indicate the presence of carbohydrates.

\section{DPPH Radical Scavenging Activity}

DPPH free radical scavenging of Piper betle methanolic extract was estimated according to the method of Blois et al.13 Free radical scavenging ability of the extract was tested using DPPH radical scavenging assay. Stock solution of the whole plant extract was prepared to concentration of 1 $\mathrm{mg} / \mathrm{mL}$. A solution of $0.1 \mathrm{mM}$ DPPH was prepared. To $1 \mathrm{~mL}$ of this solution $3 \mathrm{~mL}$ of different concentration extract in methanol were added. The mixture was shaken vigorously and allowed to stand at room temperature for 30 mins. Then, absorbance was measured at $517 \mathrm{~nm}$. By using UV-VIS Spectrophotometer, ascorbic acid was used as reference standard. Lower absorbance of the reaction mixture indicates higher free radical activity. All the tests were performed in triplicate.

The Percent DPPH Scavenging Effect was calculated by using following Equation-

DPPH scavenging effect (\%) or Percent inhibition= A0 - A1/ A $0 \times 100$. Where A0 was the Absorbance of control reaction and $\mathrm{A} 1$ was the Absorbance in presence of extract/ standard.

\section{Statistical Analysis}

Data was entered, and analysis was done using SPSS statistical software. Results of antioxidant activity with different concentration of betel leaf was expressed as mean value \pm SD. A graph was plotted using $\%$ of inhibition against concentration. A linear graph was obtained. 


\section{RESULTS}

The radical scavenging activity of methanolic leaf extract was to be determined on the basis of the radical scavenging effect on the DPPH (2, 2-diphenyl-1-picrylhydrazyl). DPPH is a stable free radical and accepts hydrogen radical to become diamagnetic molecule. The solution appears a deep violet colour and changes to yellow after accepting hydrogen. The reduction capability of DPPH radical was determined by decrease in its absorbance at $517 \mathrm{~nm}$, which is induced by antioxidants. The decrease in absorbance of DPPH radical caused by antioxidants because of the reaction between antioxidant molecules and DPPH which results in the scavenging of the radical by hydrogen donation. It is visually noticeable as a change in colour from purple to yellow. Piper betle Linn methanolic extract exhibited antioxidant activity, where ascorbic acid was used as standard at varying concentrations. There was a dose dependent increase in the percentage antioxidant activity for all concentrations tested. The tests were done in triplicates in each concentration and the mean value \pm SD of the three tests was considered. $A$ linear graph was obtained. The study reveals presence of antioxidant principles in Piper betle leaf extract.

\begin{tabular}{|c|c|c|}
\hline $\begin{array}{c}\text { Sl. } \\
\text { No. }\end{array}$ & Phytochemical Constituent & $\begin{array}{c}\text { Methanolic } \\
\text { Extract }\end{array}$ \\
\hline 1 & Alkaloids & + \\
\hline 2 & Glycosides & + \\
\hline 3 & Flavonoids & + \\
\hline 4 & Saponins & + \\
\hline 5 & Tannins & + \\
\hline 6 & Terpenoids & + \\
\hline 7 & Proteins & + \\
\hline 8 & Carbohydrates \\
\hline $\begin{array}{c}\text { Table 1. Phytochemical Screening of Methanolic Extract of } \\
\text { Piper Betle Leaf. Phytochemical composition of Plant } \\
\text { Extract }\end{array}$ \\
\hline
\end{tabular}

(+) Indicate Present and (-) Indicate Absent.

\section{Table 1}

Represents phytochemical screening of Piper betle leaf extract. Test for alkaloids, glycosides, flavonoids, tannins, terpenoids and carbohydrates are positive.

\begin{tabular}{|c|c|c|}
\hline $\begin{array}{c}\text { Sl. } \\
\text { No. }\end{array}$ & $\begin{array}{c}\text { Concentration } \\
\text { Inhibition }\end{array}$ & $\begin{array}{c}\text { Antioxidant } \\
\text { Activity } \pm \text { SD }\end{array}$ \\
\hline 1 & 37.86 & $23.93 \pm 10.04$ \\
\hline 2 & 94.67 & $51.49 \pm 13.87$ \\
\hline 3 & 189.3 & $87.09 \pm 23.34$ \\
\hline Table 2. Shows Percentage Inhibition of Methanolic Leaf \\
Extract of Piper Betle at Concentrations $(\boldsymbol{\mu g} / \mathbf{m L})$ in $\mathbf{D P P H}$ \\
Scavenging Model \\
\hline
\end{tabular}

Values are mean of three measurements.

\section{Table 2}

Shows percentage inhibition of Piper betle methanolic leaf extract at concentrations $(\mu \mathrm{g} / \mathrm{mL})$ in DPPH scavenging model.
Increasing the concentration of Piper betle $(37.86 \mu \mathrm{g}$, $94.67 \mu \mathrm{g}$ and $189.3 \mu \mathrm{g}$ ) shows a linear increase in its antioxidant activity. The mean value $(\mathrm{n}=3)$ of antioxidant activity at each concentration is $23.93 \pm 10.04,59.49 \pm 13.87$, $87.09 \pm 23.34$ respectively.

\begin{tabular}{|c|c|c|}
\hline Sl. No. & $\begin{array}{c}\text { Concentration } \\
\text { Inhibition }\end{array}$ & $\begin{array}{c}\text { Antioxidant } \\
\text { Activity } \pm \text { SD }\end{array}$ \\
\hline 1 & 0.143 & $0.82 \pm 0.01$ \\
\hline 2 & 0.28 & $16.69 \pm 0.04$ \\
\hline 3 & 0.42 & $27.34 \pm 1.1$ \\
\hline $\begin{array}{c}\text { Table 3. Shows Percentage Inhibition of Standard Ascorbic } \\
\text { Acid at Concentrations ( } \boldsymbol{\mu g} / \mathbf{m L} \text { ) in DPPH Scavenging } \\
\text { Model }\end{array}$ \\
\hline \multicolumn{2}{|c|}{} \\
\hline
\end{tabular}

Values are mean of three measurements.

\section{Table 3}

Shows percentage inhibition of standard Ascorbic Acid at concentrations $(\mu \mathrm{g} / \mathrm{mL})$ in DPPH scavenging model concentration.

Increasing the concentration of standard Ascorbic acid $(0.143 \mu \mathrm{g}, 0.28 \mu \mathrm{g}, 0.42 \mu \mathrm{g})$ shows a linear increase in its antioxidant activity. The mean value $(\mathrm{n}=3)$ of antioxidant activity at each concentration is $0.82 \pm 0.01,16.69 \pm 0.04$, $27.34 \pm 1.1$ respectively.

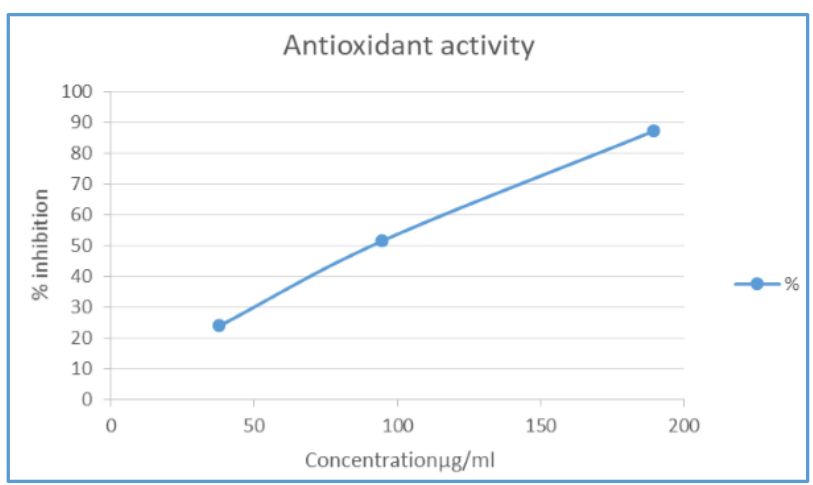

Figure 1. DPPH Free Radical Scavenging Activity of Methanolic Leaf Extract of Piper Betle Linn

\section{Figure 1}

DPPH free radical scavenging activity of methanolic leaf extract of Piper betle Linn. A straight-line graph is obtained by plotting between different concentration and $\%$ inhibition.

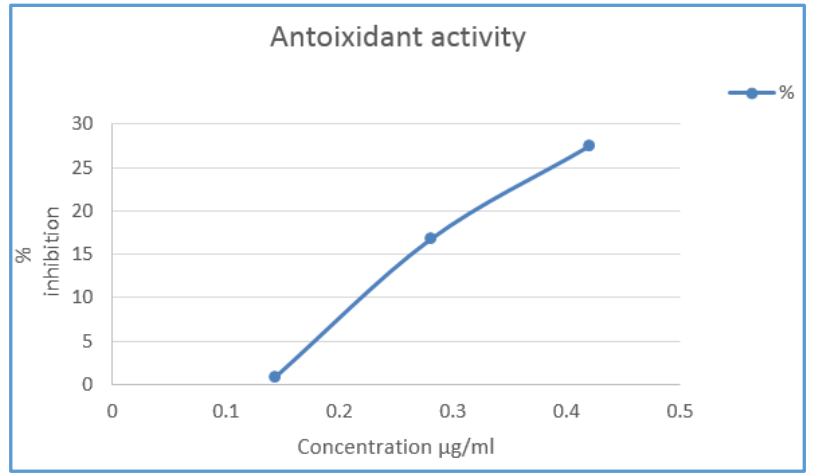

Figure 2. DPPH Free Radical Scavenging Activity of STD Ascorbic Acid 


\section{Figure 2}

DPPH free radical scavenging activity of STD Ascorbic acid. Ascorbic acid is a proven antioxidant, which is used as a standard in Antioxidant assays.

\section{DISCUSSION}

DPPH analysis is the best known accurate and frequently employed methods for evaluating antioxidant activity. In our present study, Piper betle methanolic leaf extract demonstrated significant antioxidant activity. This is comparable to the study conducted recently by Managua et al,14 which demonstrated that methanolic extract of betle leaves possess reducing power, DPPH radical and superoxide anion scavenging activities. Lei $\mathrm{D}$ et al showed in vitro nitrogen oxide scavenging effect in the hydroalcoholic extract of the betel leaf. 8

In another study conducted by Azuini MA et al also revealed that betel leaf constituents, eugenol, hydroxychavicol and alpha-tocopherol, increased glutathione levels in mouse skin and liver. ${ }^{15}$ Bhide SV et al showed an increase in the levels of reduced glutathione and enhanced glutathione S-transferase activity in betel leaf extract on benzo(a)pyrene-induced neoplasia in male Swiss mice.16

KY Pin et al also demonstrated antioxidant and antiinflammatory property using solvents with different polarities and it was identified that eugenol and Hydroxychavicol were present. ${ }^{17}$ Amonkar et al showed that Piper betle leaf extract exhibited dose-dependent suppression of dimethylbenzanthracene-induced mutagenesis in S. typhimurium strains TA98 with metabolic activation and Hydroxychavicol was more potent than eugenol in this respect. ${ }^{1}$

A study conducted by Devajan Chakraborty et al, Piper betle extract contains large number of bioactive molecules. Earlier antiulcerogenic activity of Piper betle was attributed to antioxidant property. ${ }^{18}$ Similarly, Deshpande et al demonstrated that Piper betle is used to treat bronchitis, asthma and dyspepsia. The results from various free radical scavenging system done by Nabasree Das Gupta et al revealed that three local varieties of Piper betle leaf had significant antioxidant activity. ${ }^{19}$

The Piper leaf extracts inhibits radiation-induced lipid peroxidation. The extract also increased the activity of superoxide dismutase in a dose dependent manner indicating elevation of antioxidant status in Swiss albino mice by Piper betle leaf extract was demonstrated by Dharminder et al. ${ }^{20}$

\section{CONCLUSION}

From this study, it is clear that crude extract of Piper Betle leaf contains active medicinal components. The preliminary phytochemical investigation confirms the presence of bioactive components in the extract. The result of this study on Piper betle Linn methanolic extract demonstrates significant antioxidant activity of Piper betle Linn, which can be used as easily accessible source of natural antioxidant. However, the components responsible for the antioxidant activity of methanolic extract are currently unclear. Also, the antioxidant potential of betel leaves can be demonstrated using other solvents, which may increase the performance. Thus, Piper betle can be promising source of natural antioxidants in future. Therefore, further works have to be performed on the isolation and identification of the antioxidant compounds present in the plant extract.

\section{REFERENCES}

[1] Pradhan KA, Suri KA, Pradhan DK, et al. Golden heart of the nature. Piper Betle Linn. J Pharmacog Phytochem 2013;1:147-67.

[2] Fazal P, Mane PP, Rai MP, et al. The Phytochemistry, traditional uses and pharmacology of Piper Betel Linn (Betel Leaf): a Pan-Asiatic medicinal plant. Chin J Integr Med 2014: p. 1-11.

[3] Muruganandam L, Krishna A, Reddy J, et al. Optimisation studies in extraction of Phytocomponents from betel leaves. ResourceEfficient Technologies 2017;3(4):385-93.

[4] Lim YY, Lim TT, Tee JJ. Antioxidant properties of several tropical fruits: a comparative study. Food Chem 2007;103(3):1003-8.

[5] Devasagayam TP, Tilak JC, Boloor KK, et al. Free radicals and antioxidants in human health: current status and future prospects. J Assoc Physicians India 2004;52:794-804.

[6] Rintu D, Shinjini M, Kaustab M, et al. Anti-Oxidant and Anti-Inflammatory activities of different varieties of piper leaf extracts (Piper Betle L). J Nutr Food Sci 2015;5:415.

[7] Jaiswal SG, Patel M, Saxena DK, et al. Antioxidant properties of Piper Betel (L) leaf extracts from six different Geographical domain of India. Journal of Bioresource Engineering and Technology 2014;2(2):12-20.

[8] Lei D, Chan CP, Wang YJ, et al. Antioxidants and antiplatelet effects of aqueous inflorescence Piper Betel extracts. J Agric Food Chem 2003;51(7):2083-8.

[9] Sazwi NN, Nalina T, Rahim AZH. Antioxidant and cytoprotective activities of Piper Betel, Areca catechu, Uncaria gambir and betel quid with and without calcium hydroxide. BMC Complementary and Alternative Medicine 2013;13:351.

[10] Amonkar AJ, Nagabhushan M, D'Souza AV, et al. Hydroxychavicol: a new phenolic antimutagen from betel leaf. Food Chem Toxicol 1986;24(12):1321-4.

[11] Owen PL, Matainaho T, Sirois M, et al. Endothelial cytoprotection from oxidised LDL by some crude Melanesian plant extracts is not related to their antioxidant capacity. J Biochemistry and Molecular Toxicology 2007;21(5):231-42.

[12] Ahmed A, Allarkhi AFM, Hena S, et al. Optimization of soxhlet extraction of Herba Leonuri using factorial design of experiment. Int J Chem 2010;2(1):198-205.

[13] Blois MS. Antioxidant determinations by the use of stable free radical. Nature 1958;181:1199-200.

[14] Manigauha A, Ali H, UmaMaheshwari M. Antioxidant activity of ethanolic extract of Piper betel leaves. J Pharm Res 2009;2(3):491-4.

[15] Azuine MA, Amonkar AJ, Bhide SV. Chemopreventive effcacy of betel leaf extract and its constituents on 7 , 12-dimethylbenz(a)anthracene induced carcinogenesis and their effect on drug detoxification system in mouse skin. Indian J Exp Biol 1991;29(4):346-51. 
[16] Bhide SV, Zariwala MB, Amonkar AJ, et al. Chemopreventive efficacy of a betel leaf extract against benzo[a]pyrene-induced fore stomach tumors in mice. J Ethnopharmacol 1991;34(2-3):207-13.

[17] Pin KY, Chuah LA, Rashih AA, et al. Antioxidant and anti-inflammatory activities of extracts of betel leaves (Piper Betel) from solvents with different polarities. J of Tropical Forest Science 2010;22(4):448-55.
[18] Chakraborty D, Shah B. Antimicrobial, Antioxidative and Anti-hemolytic activity of Piper Betel leaf extracts. International Journal of Pharmacy and Pharmaceutical Sciences 2011;3(Suppl 3):192-9.

[19] Dasgupta N, Bratati De. Antioxidant activity of Piper betel L. leaf extract in vitro. J Food Chem 2004;88(2):219-24.

[20] Chaoudhary D, Kale RK. Antioxidant and non-toxic properties of Piper betle leaf extract: in vitro and in vivo studies. Phytother Res 2002;16(5):461-6. 